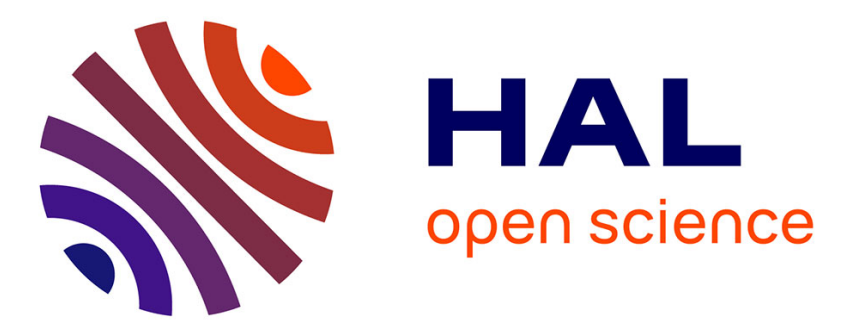

\title{
Physical Activity Levels and New Public Transit: A Systematic Review and Meta-analysis
}

Christina Xiao, Yevgeniy Goryakin, Michele Cecchini

\section{To cite this version:}

Christina Xiao, Yevgeniy Goryakin, Michele Cecchini. Physical Activity Levels and New Public Transit: A Systematic Review and Meta-analysis. American Journal of Preventive Medicine, 2019, 56, pp.464 - 473. 10.1016/j.amepre.2018.10.022 . hal-03486103

\section{HAL Id: hal-03486103 https://hal.science/hal-03486103}

Submitted on 20 Dec 2021

HAL is a multi-disciplinary open access archive for the deposit and dissemination of scientific research documents, whether they are published or not. The documents may come from teaching and research institutions in France or abroad, or from public or private research centers.
L'archive ouverte pluridisciplinaire HAL, est destinée au dépôt et à la diffusion de documents scientifiques de niveau recherche, publiés ou non, émanant des établissements d'enseignement et de recherche français ou étrangers, des laboratoires publics ou privés.

\section{(ㄷ)(1) $\$$}

Distributed under a Creative Commons Attribution - NonCommerciall 4.0 International 


\section{Physical Activity Levels and New Public Transit: A Systematic Review and}

\section{Meta-analysis}

Christina Xiao, MPH, ${ }^{1,2}$ Yevgeniy Goryakin, $\mathrm{PhD},{ }^{1}$ Michele Cecchini, $\mathrm{MD}^{1}$

From the ${ }^{1}$ Health Division, Directorate for Employment, Labour and Social Affairs, Organisation for Economic Co-operation and Development, Paris, France; and ${ }^{2}$ Masters of Public Health Program, École des Hautes Études en Sante Publique, Paris, France

Address correspondence to: Christina Xiao, MPH, 7 bis rue Christiani, Paris 75018. E-mail: cxiao94@gmail.com. 
Context: Physical inactivity is a public health concern as it contributes to the rising burden of noncommunicable diseases. Introducing new public transportation options, such as extending or building new light rail or bus rapid transit stations, could encourage commuters to walk to and from public transit stops, thus increasing their physical activity levels. Despite previous research generally finding positive associations between public transit usage and physical activity levels, few have summarized the association between introducing new public transportation options and different intensities of physical activity. This study aimed to systematically review the current evidence and perform a meta-analysis on this association.

Evidence acquisition: Ten databases were systematically searched for studies published between 1997 and 2017. To ensure comparability, study outcomes were converted to MET hours/week. A random effects meta-analysis and sensitivity analysis were then conducted. Evidence synthesis: Nine studies were identified to be included in the systematic review, of which five were eligible for meta-analysis. Pooled results suggest that building new public transit options is associated with a statistically significant increase in light to moderate physical activity levels by $1.76 \mathrm{MET}$ hours/week $(95 \% \mathrm{CI}=0.19,3.32, p=0.03)$. This is equivalent to increasing walking and other light to moderate physical activity by about 30 minutes per week, relative to baseline. No significant effect was found for the moderate to vigorous physical activity outcome. Conclusions: Results show new public transit options can substantially contribute to increasing low to moderate intensity exercise levels, which has the potential to improve health on a population scale. 


\section{CONTEXT}

Physical inactivity is the fourth leading risk factor linked to global mortality, leading to nearly 3.2 million deaths each year. ${ }^{1}$ Although physical activity (PA) is beneficial, about a third (31\%) of individuals worldwide aged 15 years and older did not reach the WHO recommended level of regular PA in $2008 .^{2}$

PA can be categorized into different intensities—light, moderate, vigorous, or in their various combinations, such as light to moderate PA (LMPA) and moderate to vigorous PA (MVPA). These activities are characterized by the amount of METs required to perform a specific PA. METs denote the energy cost of certain PAs, with higher MET values denoting more intense PA. For instance, one MET is the energy equivalent of a person seated at rest, whereas walking for transportation at 2.8-3.2 miles per hour (4.5-5.1 kilometer/hour) has a MET of 3.5. Light PA is defined as activity requiring less than $3 \mathrm{METs},{ }^{3}$ moderate PA is defined as activity requiring 3-6 METs, ${ }^{4}$ and vigorous PA is defined as activity requiring more than 6 METs. ${ }^{4}$ LMPA encapsulates lighter PA, such as walking for leisure or commute, whereas MVPA includes more intensive PA, such as cycling or running.

The WHO recommends at least 150 minutes per week of MVPA or 75 minutes per week of vigorous PA for adults aged 18-64 years, and 1 hour/day of MVPA for children aged 5-17

years. ${ }^{5,6}$ Although WHO does not explicitly mention LMPA in their guidelines, LMPA does include moderate types of PA, such as brisk walking, emphasized by WHO as beneficial to health. Promoting LMPA (and the associated health benefits) may also be easier, as it usually happens incidentally in daily living. ${ }^{3}$ 
In addition to various other benefits, public transit networks have the potential to positively impact the health of many individuals, given that two thirds of the world's population is projected to live in cities by $2050 .^{7}$ Indeed, studies have suggested that some features of the built environment, such as public transit, may increase uptake of PA. ${ }^{8-10}$ Taking public transportation has also been associated with an increased probability that individuals will meet PA recommendations through walking. ${ }^{11-15}$ For instance, public transit users were found to spend 533 more minutes walking per day than those who commute by car. ${ }^{11,16-22}$ Moreover, public transportation use can lead to a better risk factor profile; MacDonald et al. ${ }^{23}$ found that new light rail transit (LRT) users reduced their BMI by an average of $1.18 \mathrm{~kg} / \mathrm{m}^{2}$ compared with non-LRT users over a 12- to 18 -month period.

Three systematic reviews and one meta-analysis have examined effects of public transit on PA. One systematic review examined only cross-sectional associations between active travel and PA levels ${ }^{16}$ whereas the other two did not quantitatively assess changes in PA levels. ${ }^{24,25}$ Finally, a recent meta-analysis by Hirsch and colleagues ${ }^{26}$ reported an increase of 6.7 minutes/week (95\% $\mathrm{CI}=-10.1,23.5)$ of transit-related PA and a reduction of 80.4 minutes/week $(95 \% \mathrm{CI}=-157.9,-$ 2.9) in what they called total PA (the sum of walking and cycling minutes/week). The study in this article differs from the study by Hirsch in several important respects. First, the intensities of different types of PA are considered, allowing one to ascertain whether these interventions facilitate meeting PA recommendations. For instance, Hirsch et al. used transit and total PA as their main outcomes, whereas this study focused on transportation-related PA, which was further categorized into LMPA and MVPA as the main outcomes. Second, the authors explicitly 
consider the actual (or potential) effect of these interventions on PA levels in both intervention and control groups, thus enabling a more robust difference-in-difference (DID) estimation approach. Third, a number of sensitivity checks were conducted, which is important as additional assumptions were made to conduct the meta-analysis.

The aim of this study is to conduct a comprehensive systematic review and meta-analysis on the effectiveness of new public transportation options, such as LRTs, busways, and subways in promoting different intensities of PA, while also taking into account the changes in the amount of PA in both intervention and control areas. The primary outcome examined is the amount of time people spend on LMPA and MVPA in minutes. To ensure inter-study comparability, this outcome was subsequently converted into a common measure of MET hours/week.

\section{EVIDENCE ACQUISITION}

\section{Data Sources and Search Strategy}

In July of both 2017 and 2018, ten databases were systematically searched, including CINAHL, Embase, Google Scholar, Ovid, PubMed Central, PsychINFO, PubMed, Science Direct, SPORTDiscus, and Web of Science. Search terms included (LMPA OR MVPA OR $c y c l^{*}$ OR exercise OR walk* OR physical activity) AND (public transportation OR mass transit OR public transit $\mathrm{OR}$ bus rapid transit $\mathrm{OR}$ intermodal transportation $\mathrm{OR}$ transitway OR busway OR light rail) AND (construction OR natural experiment).

\section{Inclusion and Exclusion Criteria}

To be included, studies needed to fulfill the following eligibility criteria: (1) be published in the last 20 years, or between 1997 and 2018; (2) consider the effect of building, extending, or 
improving local public transit options; (3) measure as an outcome variable levels of PA in minutes, steps, or distance per set period of time; (4) have relevant comparison groups; (5) have an RCT, longitudinal, quasi-experimental, or a before-and-after study design; (6) report pre- and post-PA levels, change in PA in at least the intervention group, or differences between the intervention and control group with corresponding 95\% CIs and SDs; and (7) be written in English. Studies that fulfilled all inclusion criteria and had results that could be pooled with other studies were included in the meta-analysis. It is also worth noting that the Foley and colleagues ${ }^{27}$ study intervention is described in a report of a larger series of studies examining a new bus rapid transit (BRT) system. ${ }^{28}$

\section{Risk of Bias}

The Effective Public Health Practice Project was used to evaluate study quality. ${ }^{29}$ This tool has been used for public health research, including public health intervention studies. ${ }^{30,31}$ Study quality was determined based on six criteria: selection bias, study design, confounders, blinding, data collection methods, and withdrawals and dropouts. Of the nine included studies, all were rated moderate in the study design dimension as they were observational studies (Appendix Table 1). Most studies had issues with selection bias, low study participant recruitment, and dropouts; in several studies, however, the confounders dimension was rated as strong either because there were no important differences between groups prior to the intervention or they controlled for confounders (Appendix Table 1).

\section{Statistical Analysis}

Although nine potentially relevant studies were identified in the systematic review (Appendix Table 2), ${ }^{27,32-39}$ only five were eligible for meta-analysis due to the lack of comparable study 
outcomes and study design duplication..$^{27,34,36-38}$ When two studies were found to examine the same population and intervention, only the most recent one was included in the meta-analysis. Because the outcome variable differed between studies, they were all converted based on the WHO PA guidelines or the 2011 Adult Compendium of Physical Activities ${ }^{4,40}$ into a standard outcome variable, or MET hours/week (Appendix Table 3 provides more information about conversion factors). ${ }^{\text {a }}$ Time was converted into LMPA if the study reported walking activity, and into MVPA if the study reported cycling activity, ${ }^{27,34,37}$ whereas two other studies directly reported on either LMPA or MVPA. ${ }^{36,38}$ When studies reported both LMPA and MVPA outcomes, results for each outcome were considered as an independent study. LMPA and MVPA outcomes were stratified when conducting the meta-analysis to determine if public transit affects these two PA levels differently. Extracted data from the studies included number of participants, study duration, and the mean and SD of number of minutes spent on LMPA and MVPA for both intervention and control groups.

A DID analysis was conducted to determine the overall intervention effects along with their SEs and CIs. ${ }^{41}$ Studies provided either already weighted DID estimates, ${ }^{38}$ or pre- and postintervention data (which were transformed into DID estimates) for both intervention and control groups. ${ }^{27,34,36,37}$ Appendix Text 1 provides more information about the estimation methodology.

To calculate the differences in PA levels over time, the intervention and control groups were defined for each study. Most studies (four of five) used distance from new public transit stops as a measure of exposure, with the median catchment area being 0.7 kilometers (range, 0.4-30

${ }^{\mathrm{a}}$ Formally, one MET is equal to the cost of oxygen consumption while sitting quietly, or $3.5 \mathrm{~mL} \mathrm{O} 2 / \mathrm{kg}$ /min. More intuitively, one MET of energy spending is equal to 1 kilocalorie/kilogram/hour. 
kilometers). ${ }^{27,34,36,37}$ Thus, those who lived within these areas were considered the intervention group, whereas those who lived beyond these areas were the control group. The only exception

was the study by Miller et al., ${ }^{37}$ where the intervention group was considered to be new public transit riders (those who did not ride public transit the first year) and the control group was continuing riders (those who rode public transit both years).

The results of five studies ${ }^{27,34,36-38}$ were pooled together to estimate a summary effect size along with its 95\% CI for both LMPA and MVPA. The "metan" package was used in Stata, version 14.0 to create a meta-analysis model, which places more weight on studies with larger sample sizes. A less restrictive random effects estimator was used. Study heterogeneity was calculated by using a visual inspection of the forest plots and the $\mathrm{I}^{2}$ statistic. Publication bias was then examined using a funnel plot and the Egger test using the "metabias" Stata package.

\section{Sensitivity Analysis}

The robustness of the findings was assessed by conducting several sensitivity checks. Specifically, studies that were considered to have a weak cumulative score or global rating as determined by the Effective Public Health Practice Project tool were removed. Furthermore, studies that had $<1$ year of follow-up were removed in a separate sensitivity analysis to allow for sufficient time for traveling habits to form and to account for seasonal effects. In addition, a fixed effects analysis was conducted. Finally, two meta-regressions were run to test any potential effect on the PA effect size produced by modifying either the follow-up length or the catchment area.

\section{EVIDENCE SYNTHESIS}




\section{Search Strategy and Study Identification}

In the first round, the titles and key words of 2,640 studies were screened according to the criteria outlined above (Figure 1). The screening excluded a large proportion of duplicate studies ( $n=713$ ), which left 1,946 studies to be screened by title. A total of 241 studies were left to be screened through their abstracts. A further 144 studies were excluded, leaving 97 full texts to be examined. There were 88 studies ineligible due to various reasons, such as no relevant intervention ( $n=30)$, no relevant outcome $(n=30)$, reviews that were used for references $(n=22)$, studies that were inaccessible $(n=3)$, protocol papers $(n=2)$, or the study design was duplicated in another published study $(n=1)$. Nine studies were considered for the qualitative analysis, of which five were included in the quantitative meta-analysis. The remaining four studies either duplicated another study's study design and population, or reported the outcomes in medians or IQRs, which could not be pooled together with the other studies.

\section{Qualitative Review}

All nine studies eligible for systematic review were published between 2013 and 2017 and included subjects from the U.S. ( $n=5)$, United Kingdom ( $n=2)$, Canada ( $n=1)$, and Mexico $(n=1$; Appendix Table 2) ${ }^{27,32-39}$ All studies had a quasi-experimental longitudinal before-and-after research design. Follow-up time between baseline and post-intervention surveys varied between 5 months to 2 years (mean=13.89 months, $\mathrm{SD}=6.17$ ). There was a total of 4,249 subjects included in both pre-and post-phases of the studies, and sample sizes varied greatly from 71 to 2,487 subjects (mean=472.11, SD=783.41). Interventions included adding LRT stations to

extend existing LRT systems as their intervention,,$^{32,33,36-38}$ or adding BRT lines. ${ }^{27,34,35,39}$ 
In all reviewed studies, the outcomes were measured in either minutes per day or per week. The majority ( $n=6)$ assessed PA duration and intensity using a combined sensor (Actiheart) or accelerometers (GT1M or GT3x+, Actigraph) along with GPS loggers (GlobalSat DG$100),{ }^{27,32,33,36-38}$ whereas the remainder used self-reported data collected from surveys $(\mathrm{n}=3) .{ }^{34,35,39}$ All studies using GPS and accelerometer devices collected PA data for 1 week after the end of the follow-up.

\section{Intervention Effects by Intensity of Exercise}

In some studies, the effect on both LMPA and MVPA was reported. ${ }^{27,32-34,36,37,39}$ Eight of nine studies selected for systematic review reported one of the LMPA-associated measures as an outcome. $^{27,32-35,37-39}$ Walking time was one of the most prevalent outcomes. All studies found a positive effect of new public transportation options on time spent in PA, though not all were statistically significant. Two studies in the United Kingdom found an insignificant increase in LMPA. $^{27,39}$ Of the three studies examining the construction of new LRT stops in the U.S., one found an insignificant increase in the number of walking minutes compared with before the intervention $^{32}$; the significance of the change in time spent on PA in the other two articles was not reported. ${ }^{33,37}$ Another study conducted in the U.S. found that living closer to the new transit station was significantly associated with increased walking and PA amongst individuals who had previously low walking and PA levels. ${ }^{36}$ In Canada, introducing three new express transit service routes significantly increased transit ridership from 5.5\% to $8.5 \%(p<0.001)$ among university employees, with transit riders_-defined as those who walk to and from the bus stopaccumulating an average of 50 minutes/week of commute-related PA more than those who commuted entirely passively. ${ }^{35}$ In Mexico, introducing a new BRT line increased walking duration for individuals living closer to the intervention by almost 30 minutes/week. ${ }^{34}$ 
Of the studies reporting MVPA outcome estimates, cycling was one of the most prevalent forms of MVPA. Two studies found a statistically insignificant negative effect of increasing public transit access on MVPA. ${ }^{27,36}$ One of the studies did find, however, that when controlling for baseline MVPA levels, there was a significant increase in activity for participants who had previously low levels of MVPA living closer to the station, compared with those who already had high levels of MVPA, suggesting potential effect modification. ${ }^{36}$ The five remaining studies found a positive effect, though only two found statistically significant results. ${ }^{33,39}$

Four studies found through the systematic review were not included in the meta-analysis due to the limitations of study design and incompatibility of outcome measures reported with the other studies in the meta-analysis. For instance, Collins and Agarwal $^{35}$ did not report a baseline PA measure to be able to compare with post-intervention results. Panter and colleagues ${ }^{39}$ found that individuals increased their cycling time by a median of 10 minutes. However, from a statistical standpoint, it is not possible to pool this median with the mean values reported in other studies without additional information about the distribution of the study sample. The studies by Brown et al. ${ }^{32}$ and Miller and colleagues ${ }^{33}$ had nearly identical study designs and subjects, differing mainly in the estimation approach. Likewise, studies by Boarnet et al. ${ }^{37}$ and Huang and colleagues $^{38}$ had nearly identical designs and subjects, with only the outcome measures being different. Of these four studies, only the studies by Miller et al. ${ }^{37}$ and Huang and colleagues ${ }^{38}$ were included in the meta-analysis model as they are more recent. Thus, a meta-analysis was conducted on five eligible studies, ${ }^{27,34,36-38}$ with some studies reporting independent LMPA and MVPA outcomes (Table 1). 27,34,37 
Table 1 and Figure 2 presents the overall effect of introducing new public transportation options on either LMPA or MVPA. All LMPA studies exhibited positive effects, two of which were statistically significant, ${ }^{34,37}$ whereas only one study had a statistically significant effect in the MVPA category. ${ }^{37}$ The overall pooled effect was positive and statistically significant (1.06 MET hours/week, $95 \% \mathrm{CI}=0.12,2.01, p=0.03)$, but there was evidence of heterogeneity $\left(\mathrm{I}^{2}=74.10 \%\right.$, $P_{\text {heterogeneity }}=0.000 ;$ Appendix Table 4). The increase in PA was mainly driven by the statistically significant effect of introducing public transportation options on LMPA (1.76 MET hours/week, $95 \% \mathrm{CI}=0.19,3.32, p=0.03)$. Some evidence for heterogeneity was observed for LMPA studies $\left(\mathrm{I}^{2}=73.60 \%, P_{\text {heterogeneity }}=0.01\right.$; Appendix Table 4$)$. The pooled effect size for the MVPA studies was statistically insignificant (0.33 MET hours/week, 95\% CI= -0.71, 1.38, $p=0.53$; Appendix Table 4).

The Egger test of the null hypothesis of no small-study effects for LMPA and MVPA was 0.82 and 0.68, respectively (Appendix Figure 1). Thus, it can be assumed that smaller studies did not exhibit different or larger treatment effects than larger studies. Moreover, the funnel plot suggests little evidence for publication bias, though because of the small number of articles included, bias results should be treated with caution (Appendix Figure 2).

\section{Sensitivity Analysis}

Table 2 presents results from the sensitivity checks based on quality of study, follow-up duration, and fixed effects assumption. Including only moderate-quality studies (Appendix Table 1) as indicated by the risk of bias global rating decreased the LMPA effect size and increased the MVPA effect size from 0.332 to 1.777 . This resulted in a nonsignificant LMPA and overall 
pooled effect, whereas the MVPA pooled effects remained nonsignificant. When studies were restricted to those with $>1$ year of follow-up, one study was removed from the MVPA group (and none from the LMPA group), which did not change the significance of the effect size. Using a fixed effects meta-analysis model, none of the pooled groups changed significance. Furthermore, results from meta-regressions between PA effect size and either study follow-up length or catchment area (Appendix Table 2) showed no significant differences $(p=0.446$ and 0.312, respectively; Appendix Table 5).

\section{DISCUSSION}

This systematic review and meta-analysis demonstrated that constructing new public transit options is likely to result in a sizeable increase in the amount of LMPA performed, but not for MVPA performed. Specifically, this meta-analysis has shown that in response to the introduction of new public transit options, public transit users could increase their PA levels (averaged over LMPA and MVPA) by 1.06 MET hours/week and by 1.76 MET hours/week for LMPA.

The WHO recommends performing at least 150 minutes of moderate PA. From the assumption that LMPA activities are performed, on average, at the lower bound of energy expenditure for moderate activities (MET=3.0), the findings from this study show an increase of about 35 minutes, or approximately one fifth of the WHO recommendation. Because such an increase would be in addition to the amount of PA already undertaken, individuals can substantially benefit from increased access to public transit. Furthermore, switching from car to public transit use can have a number of other benefits, such as improvements in psychological wellbeing, ${ }^{42}$ 
reduction in traffic-related air pollution, better air quality, and subsequent improvements in respiratory health outcomes. ${ }^{43}$

The results for the MVPA outcome were not significant, which may be due to the fact that individuals are more likely to walk than to cycle to public transit stops-in part because cyclists need appropriate cycling infrastructure, such as bicycle parking or lockers. At the same time, this finding suggests that isotemporal substitution is unlikely to be an issue: although people may compensate for walking more to get to the public transportation stops by reducing their other types of PA, the results in this study found that while LMPA increases, MVPA did not decrease. This is corroborated by another study which found that there were positive associations between time spent on leisure PA and active transportation time. ${ }^{44}$

In one systematic review on a similar topic, Rissel et al. found that public transit users gain 8-33 more minutes of walking per day (56-231 minutes of LMPA per week) than car riders. ${ }^{16}$ The estimates found in this meta-analysis are at the lower end of this range; this may be because the values in this range were based on cross-sectional studies, which are less likely to identify causal effect.

The meta-analysis by Hirsch and colleagues ${ }^{26}$ found an insignificant increase in transport-related PA, though they combined walking and cycling activities into one time measure. Thus, the current study provides additional information on changes in energy expenditures separately for LMPA and MVPA dimensions, likely to be causally attributed to the introduction of new public transportation options. 
This study has several strengths. First, the number of articles included in the meta-analysis was maximized by converting all outcomes into a single measure of PA or MET hours/week. Second, all the studies reviewed were longitudinal and of natural experimental design, and therefore more likely to identify causal effect, compared with studies that compare PA levels cross-sectionally. Third, the pooled effect was estimated separately for LMPA and MVPA outcomes, and therefore took intensity of the exercise into account. Fourth, the majority of studies included used objective means of reporting PA, with only one study using the self-reporting International Physical Activity Questionnaire (IPAQ). Lastly, several sensitivity checks were conducted to take into account the effect on findings of study quality, length of follow-up, catchment area, and fixed effect analysis. The findings were also robust to a range of assumptions on the withingroup correlation coefficient (Appendix Table 6).

\section{Limitations}

One of the limitations of this meta-analysis was the number of studies that could be included; thus, conclusions drawn from this study should be treated with caution. Furthermore, only observational studies could be included, which may be subject to some degree of bias resulting, for example, from nonrandom assignment of transport infrastructural investments. ${ }^{b}$ However, this was unavoidable due to the nature of the intervention. On the positive note, results from such studies are more likely to be indicative of real-world policy applications.

\footnotetext{
${ }^{\mathrm{b}}$ For example, wealthier areas may be more likely to receive such investments. If prior trends in average PA levels differ between poorer and richer areas (because people living in the latter may have healthier lifestyles), then DID estimates may be confounded if such trends are not controlled for.
} 
Other limitations included the inability to perform a country-specific analysis because of a limited number of studies. Studies also had different lengths of follow-up, with catchment areas varying between 400 meters and 30 kilometers. However, as seen in the meta-regression between PA effect size and either follow-up length or catchment area, there were no significant differences between studies (Appendix Table 5). In one study, ${ }^{38}$ intervention and control catchment areas were defined as people living within 0.25 and $0.75-1$ miles away from the new mass transit stations respectively. However, the control catchment area may still include people who are affected by the station proximity, and the effect of the new transportation infrastructure may be underestimated in this case. Other limitations included the inability to perform a countryspecific analysis because of a limited number of studies. Furthermore, intervention and control groups in the Miller et al. study should be treated with caution as they were not as clearly defined as in the other selected studies, as it compared new and existing transit users before and after the introduction of the intervention.

In some studies, additional features such as new bike lanes or sidewalks were also included, ${ }^{27,37,39}$ which makes it more difficult to attribute the estimated effect exclusively to the new public transit. Furthermore, the effect sizes could have differed depending on the number of stops added, whether there was existing public transit infrastructure, and whether new infrastructure was well connected to places of interest in the city. However, such information was either unavailable or impossible to take into account in the meta-analysis.

Although almost all the reviewed studies collected objectively measured PA information, one study in the meta-analysis used self-reported data from surveys, such as the IPAQ, ${ }^{34}$ which often 
correlate strongly with walking but overestimate moderate PA trip duration compared with more objective activity monitors, such as GPS. ${ }^{45,46}$ However, this study did not report a particularly outlying result. Finally, when outcome measures were in minutes per day, the same level of PA was assumed for every day of the week, which may not always be accurate because individuals have different work and leisure PA habits on different days of the week.

\section{CONCLUSIONS}

This systematic review and meta-analysis found that public transit interventions can increase PA levels by up to one fifth of the recommended PA levels by the WHO. Further investigations using high-quality research designs are needed, particularly studies that improve subject retention with longer follow-up to allow commuting habits to form, as well as studies with welldefined and comparable intervention and control areas from a wider selection of countries. 


\section{ACKNOWLEDGMENTS}

The views expressed in this paper are those of the authors and do not necessarily reflect those of the Organisation for Economic Co-operation and Development (OECD) or its member countries. CX was responsible for writing the final manuscript, as well as conducting the systematic review and meta-analysis, whereas YG and MC conceptualized and provided feedback for the study. All authors contributed to the understanding of the analyses, reviewed, revised, and approved the final submitted manuscript.

The OECD program of work on obesity is supported by a number of voluntary contributions by Ministries of Health or other national governmental institutions of OECD member countries or other key partners.

No financial disclosures were reported by the authors of this paper. 


\section{REFERENCES}

1. WHO. Physical activity. www.who.int/ncds/prevention/physical-activity/en/. Published 2018. Accessed July 24, 2018.

2. WHO. Physical inactivity: a global public health problem. WHO. www.who.int/dietphysicalactivity/factsheet_inactivity/en/. Published 2014. Accessed July 24, 2018.

3. Chastin SFM, De Craemer M, De Cocker K, et al. How does light-intensity physical activity associate with adult cardiometabolic health and mortality? Systematic review with meta-analysis of experimental and observational studies. Br J Sports Med. In press. Online April 25, 2018. https://doi.org/10.1136/bjsports-2017-097563.

4. WHO. What is moderate-intensity and vigorous-intensity physical activity? www.who.int/dietphysicalactivity/physical_activity_intensity/en/. Published 2014. Accessed July 24, 2018.

5. WHO. Physical activity and adults. www.who.int/dietphysicalactivity/factsheet_adults/en/. Published 2015. Accessed July $24,2018$.

6. WHO. Physical activity and young people. www.who.int/dietphysicalactivity/factsheet_young_people/en/. Published 2015. Accessed July 24, 2018.

7. UN. World Urbanization Prospects: The 2018 Revision. https://esa.un.org/unpd/wup/Publications/Files/WUP2018-KeyFacts.pdf. Published 2018. Accessed July 24, 2018. 
8. Brownson RC, Hoehner CM, Day K, Forsyth A, Sallis JF. Measuring the built environment for physical activity. Am J Prev Med. 2009;36(4):S99-S123.e12. https://doi.org/10.1016/j.amepre.2009.01.005.

9. Ferdinand AO, Sen B, Rahurkar S, Engler S, Menachemi N. The relationship between built environments and physical activity: a systematic review. Am J Public Health. 2012;102(10):e7-e13. https://doi.org/10.2105/AJPH.2012.300740.

10. Sallis JF, Floyd MF, Rodriguez DA, Saelens BE. Role of built environments in physical activity, obesity, and cardiovascular disease. Circulation. 2012;125(5):729-737. https://doi.org/10.1161/CIRCULATIONAHA.110.969022.

11. Besser L, Dannenberg A. Walking to public transit: steps to help meet physical activity recommendations. Am J Prev Med. 2005;29(4):273-280. https://doi.org/10.1016/j.amepre.2005.06.010.

12. Greenberg M, Renne J, Lane R, Zupan J. Physical activity and use of suburban train stations: an exploratory analysis. J Public Transp. 2005;8(3):89-116. https://doi.org/10.5038/2375-0901.8.3.5.

13. Stokes RJ, MacDonald J, Ridgeway G. Estimating the effects of light rail transit on health care costs. Health Place. 2008;14(1):45-58. https://doi.org/10.1016/j.healthplace.2007.04.002.

14. Lachapelle U, Pinto DG. Longer or more frequent walks: examining the relationship between transit use and active transportation in Canada. J Transp Health. 2016;3(2):173180. https://doi.org/10.1016/j.jth.2016.02.005.

15. Wasfi RA, Ross NA, El-Geneidy AM. Achieving recommended daily physical activity levels through commuting by public transportation: unpacking individual and contextual 
influences. Health Place. 2013;23:18-25.

https://doi.org/10.1016/j.healthplace.2013.04.006.

16. Rissel C, Curac N, Greenaway M, Bauman A. Physical activity associated with public transport use: a review and modelling of potential benefits. Int J Environ Res Public Health. 2012;9(7):2454-2478. https://doi.org/10.3390/ijerph9072454.

17. Wener RE, Evans GW. A morning stroll: levels of physical activity in car and mass transit commuting. Environ Behav. 2007;39(1):62-74. https://doi.org/10.1177/0013916506295571.

18. Edwards RD. Public transit, obesity, and medical costs: assessing the magnitudes. Prev Med (Baltim). 2008;46(1):14-21. https://doi.org/10.1016/j.ypmed.2007.10.004.

19. Villanueva K, Giles-Corti B, McCormack G. Achieving 10,000 steps: a comparison of public transport users and drivers in a university setting. Prev Med (Baltim). 2008;47(3):338-341. https://doi.org/10.1016/j.ypmed.2008.03.005.

20. Lachapelle U, Frank L, Saelens BE, et al. Commuting by public transit and physical activity: where you live, where you work, and how you get there. J Phys Act Health. 2011;8(suppl 1):S72-S82. https://doi.org/10.1123/jpah.8.s1.s72.

21. Freeland AL, Banerjee SN, Dannenberg AL, Wendel AM. Walking associated with public transit: moving toward increased physical activity in the United States. Am J Public Health. 2013;103(3):536-542. https://doi.org/10.2105/AJPH.2012.300912.

22. Bartels C, Kolbe-Alexander T, Behrens R, Hendricks S, Lambert E V. Can the use of Bus Rapid Transit lead to a healthier lifestyle in urban South Africa? The SUN study. $J$ Transp Health. 2016;3(2):200-210. https://doi.org/10.1016/j.jth.2016.04.003. 
23. MacDonald JM, Stokes RJ, Cohen DA, Kofner A, Ridgeway GK. The effect of light rail transit on body mass index and physical activity. Am J Prev Med. 2010;39(2):105-112. https://doi.org/10.1016/j.amepre.2010.03.016.

24. Karmeniemi M, Lankila T, Ikaheimo T, et al. The built environment as a determinant of physical activity: a systematic review of longitudinal studies and natural experiments. Ann Behav Med. 2018;52(3):239-251. https://doi.org/10.1093/abm/kax043.

25. Smith M, Hosking J, Woodward A, et al. Systematic literature review of built environment effects on physical activity and active transport - an update and new findings on health equity. Int J Behav Nutr Phys Act. 2017;14(1):158. https://doi.org/10.1186/s12966-017-0613-9.

26. Hirsch JA, DeVries DN, Brauer M, Frank LD, Winters M. Impact of new rapid transit on physical activity: a meta-analysis. Prev Med Rep. 2018;10:184-190. https://doi.org/10.1016/j.pmedr.2018.03.008.

27. Foley L, Panter J, Heinen E, Prins R, Ogilvie D. Changes in active commuting and changes in physical activity in adults: a cohort study. Int J Behav Nutr Phys Act. 2015;12(1):161. https://doi.org/10.1186/s12966-015-0323-0.

28. Ogilvie D, Panter J, Guell C, Jones A, Mackett R, Griffin S. Health impacts of the Cambridgeshire Guided Busway: a natural experimental study. Public Health Res. 2016;4(1). https://doi.org/10.3310/phr04010.

29. Thomas H, Ciliska D. Quality Assessment Tool for Quantitative Studies. https://merst.ca/wp-content/uploads/2018/02/quality-assessment-tool_2010.pdf. Published 2009. Accessed July 24, 2018. 
30. Chillón P, Evenson KR, Vaughn A, Ward DS. A systematic review of interventions for promoting active transportation to school. Int J Behav Nutr Phys Act. 2011;8(1):10. https://doi.org/10.1186/1479-5868-8-10.

31. Thomson H, Thomas S, Sellstrom E, Petticrew M. The health impacts of housing improvement: a systematic review of intervention studies from 1887 to 2007. Am J Public Health. 2009;99(suppl 3):S681-S692. https://doi.org/10.2105/AJPH.2008.143909.

32. Boarnet MG, Houston D, Spears S. The Exposition Light Rail Line Study: "BeforeAfter" Opening Travel Impacts and New Resident Sample Preliminary Analysis. Lincoln Institute of Land Policy. www.lincolninst.edu/publications/working-papers/expositionlight-rail-line-study. Published 2013. Accessed July 24, 2018.

33. Brown BB, Werner CM, Tribby CP, Miller HJ, Smith KR. Transit use, physical activity, and body mass index changes: objective measures associated with complete street lightrail construction. Am J Public Health. 2015;105(7):1468-1474. https://doi.org/10.2105/AJPH.2015.302561.

34. Chang A, Miranda-Moreno L, Cao J, Welle B. The effect of BRT implementation and streetscape redesign on physical activity: a case study of Mexico City. Transp Res Part A Policy Pract. 2017;100:337-347. https://doi.org/10.1016/j.tra.2017.04.032.

35. Collins PA, Agarwal A. Impacts of public transit improvements on ridership, and implications for physical activity, in a low-density Canadian city. Prev Med Rep. 2015;2:874-879. https://doi.org/10.1016/j.pmedr.2015.10.001.

36. Hong A, Boarnet MG, Houston D. New light rail transit and active travel: a longitudinal study. Transp Res Part A Policy Pract. 2016;92:131-144. https://doi.org/10.1016/j.tra.2016.07.005. 
37. Miller HJ, Tribby CP, Brown BB, et al. Public transit generates new physical activity: evidence from individual GPS and accelerometer data before and after light rail construction in a neighborhood of Salt Lake City, Utah, USA. Health Place. 2015;36:817. https://doi.org/10.1016/j.healthplace.2015.08.005.

38. Huang R, Moudon AV, Zhou C, Stewart OT, Saelens BE. Light rail leads to more walking around station areas. J Transp Health. 2017;6:201-208. https://doi.org/10.1016/j.jth.2017.02.002.

39. Panter J, Heinen E, Mackett R, Ogilvie D. Impact of new transport infrastructure on walking, cycling, and physical activity. Am J Prev Med. 2016;50(2):e45-e53. https://doi.org/10.1016/j.amepre.2015.09.021.

40. Ainsworth BE, Haskell WL, Herrmann SD, et al. 2011 compendium of physical activities. Med Sci Sport Exerc. 2011;43(8):1575-1581. https://doi.org/10.1249/MSS.0b013e31821ece12.

41. Dimick JB, Ryan AM. Methods for evaluating changes in health care policy. JAMA. 2014;312(22):2401-2402. https://doi.org/10.1001/jama.2014.16153.

42. Martin A, Goryakin Y, Suhrcke M. Does active commuting improve psychological wellbeing? Longitudinal evidence from eighteen waves of the British Household Panel Survey. Prev Med (Baltim). 2014;69:296-303. https://doi.org/10.1016/j.ypmed.2014.08.023.

43. Giles LV, Barn P, Künzli N, et al. From good intentions to proven interventions: effectiveness of actions to reduce the health impacts of air pollution. Environ Health Perspect. 2010;119(1):29-36. https://doi.org/10.1289/ehp.1002246. 
44. Lachapelle U, Frank LD, Sallis JF, Saelens BE, Conway TL. Active transportation by transit-dependent and choice riders and potential displacement of leisure physical activity. J Plan Educ Res. 2016;36(2):225-238. https://doi.org/10.1177/0739456X15616253.

45. Lee PH, Macfarlane DJ, Lam T, Stewart SM. Validity of the international physical activity questionnaire short form (IPAQ-SF): a systematic review. Int J Behav Nutr Phys Act. 2011;8(1):115. https://doi.org/10.1186/1479-5868-8-115.

46. James P, Weissman J, Wolf J, et al. Comparing GPS, log, survey, and accelerometry to measure physical activity. Am J Health Behav. 2016;40(1):123-131. https://doi.org/10.5993/AJHB.40.1.14. 


\section{LIST OF FIGURES}

Figure 1. Systematic review search strategy.

Figure 2. Forest plot of natural experiment studies with light to moderate physical activity outcomes (MET hours/week) after transit interventions.

Notes: Quality refers to the global rating of the study quality as determined in Appendix Table 1, with 1 denoting "Weak" and 2 denoting "Moderate". The overall pooled effect is positive and statistically significant (1.062 MET hours/week; 95\% CI=0.116, 2.009; $p=0.028)$. This finding was mainly driven by the statistically significant effect of introducing public transportation options on light to moderate physical activity (1.757 MET hours/week; 95\% CI=0.190, 3.324; $p=0.028$ ). The pooled effect size for the moderate to vigorous physical activity studies was not statistically significant $(0.332$ MET hours/week; $95 \% \mathrm{CI}=-0.712,1.377 ; p=0.533)$. 
Table 1. Meta-Analysis Results

\begin{tabular}{|c|c|c|c|c|c|c|c|}
\hline Study & $\begin{array}{l}\text { Physical activity } \\
\text { type }\end{array}$ & $\begin{array}{c}\text { Effect size } \\
\text { minutes/week } \\
(95 \% \text { CI }) \\
\end{array}$ & $\begin{array}{c}\text { Effect size MET } \\
\text { hours/week } \\
(95 \% \text { CI }) \\
\end{array}$ & $\mathbf{S E}$ & $\begin{array}{c}\% \\
\text { Weight }\end{array}$ & $\mathbf{I}^{2}$ & $p$-value \\
\hline \multicolumn{8}{|l|}{$\begin{array}{l}\text { Light to moderate } \\
\text { physical activity ol }\end{array}$} \\
\hline Chang et al., 2017 & $\begin{array}{l}\text { Walking for } \\
\text { transport and/or } \\
\text { recreation }\end{array}$ & $38.05(18.50,57.60)$ & $2.22(1.08,3.36)$ & 0.58 & 16.28 & - & - \\
\hline Foley et al., 2015 & Walking & $0.9(-17.29,19.09)$ & $0.05(-1.01,1.11)$ & 0.54 & 16.81 & - & - \\
\hline Huang et al., 2017 & Station area walking & $34.30(-10.08,78.68)$ & $2.00(-0.59,4.59)$ & 1.30 & 8.22 & - & - \\
\hline Miller et al., 2015 & $\begin{array}{l}\text { Light to moderate } \\
\text { physical activity }\end{array}$ & $56.84(17.85,95.82)$ & $3.55(1.12,5.99)$ & 1.23 & 8.83 & - & - \\
\hline $\begin{array}{l}\text { Subtotal random effects } \\
\text { pooled effect size }\end{array}$ & & & 1.76* $^{*}(0.19,3.32)$ & - & 50.13 & $73.60 \%$ & 0.03 \\
\hline \multicolumn{8}{|l|}{$\begin{array}{l}\text { Moderate to vigorous } \\
\text { physical activity outcome }\end{array}$} \\
\hline Chang et al., 2017 & Cycling for transport & $3.48(-3.91,10.87)$ & $0.39(-0.44,1.23)$ & 0.43 & 18.26 & - & - \\
\hline Foley et al. 2015 & Cycling & $-10.90(-36.53,14.73)$ & $-1.24(-4.14,1.67)$ & 1.47 & 7.09 & - & - \\
\hline Hong et al., 2016 & $\begin{array}{l}\text { Moderate to } \\
\text { vigorous physical } \\
\text { activity }\end{array}$ & $-0.32(-5.47,4.83)$ & $-0.04(-0.59,0.52)$ & 0.28 & 19.84 & - & - \\
\hline Miller et al., 2015 & $\begin{array}{l}\text { Moderate to } \\
\text { vigorous physical } \\
\text { activity }\end{array}$ & $46.69(10.99,82.39)$ & $5.06(1.19,8.92)$ & 1.95 & 4.68 & - & - \\
\hline $\begin{array}{l}\text { Subtotal random effects } \\
\text { pooled effect size }\end{array}$ & & & $0.33(-0.71,1.38)$ & - & 49.87 & $61.60 \%$ & 0.53 \\
\hline $\begin{array}{l}\text { Overall random effects } \\
\text { pooled effect size }\end{array}$ & & & 1.06* $(0.12,2.01)$ & - & 100.00 & $74.10 \%$ & 0.03 \\
\hline
\end{tabular}

Notes: Boldface indicates statistical significance $\left({ }^{*} p<0.05 ; *^{*} p<0.01 ; * * * p<0.001\right)$. 
Table 2. Sensitivity Analysis of Studies

\begin{tabular}{|c|c|c|}
\hline Sensitivity test/Physical activity type & Effect size (95\% CI) & Significance \\
\hline \multicolumn{3}{|l|}{ None (studies $=5$ ) } \\
\hline Light to moderate physical activity & $1.757(0.190,3.324)$ & 0.028 \\
\hline Moderate to vigorous physical activity & $0.332(-0.712,1.377)$ & 0.533 \\
\hline Overall & $1.062(0.116,2.009)$ & 0.028 \\
\hline \multicolumn{3}{|c|}{ Only moderate quality studies ${ }^{36,38,39}$ (studies=3) } \\
\hline Light to moderate physical activity & $1.653(-0.598,3.904)$ & 0.150 \\
\hline Moderate to vigorous physical activity & $1.777(-4.385,7.939)$ & 0.572 \\
\hline Overall & $1.623(-0.358,3.604)$ & 0.108 \\
\hline \multicolumn{3}{|c|}{$\begin{array}{l}\text { Studies with at least a } 1 \text { year follow-up } \\
\text { (studies }=4 \text { ) }\end{array}$} \\
\hline Light to moderate physical activity & $1.757(0.190,3.324)$ & 0.028 \\
\hline Moderate to vigorous physical activity & $0.998(-1.616,3.612)$ & 0.454 \\
\hline Overall & $1.380(0.216,2.545)$ & 0.020 \\
\hline \multicolumn{3}{|l|}{ Fixed effects (studies $=5$ ) } \\
\hline Light to moderate physical activity & $1.342(0.631,2.054)$ & 0.000 \\
\hline Moderate to vigorous physical activity & $0.133(-0.322,0.589)$ & 0.566 \\
\hline Overall & $0.485(0.101,0.868)$ & 0.013 \\
\hline
\end{tabular}


Records identified through database search $(n=2,640)$
Additional records identified through other sources such as works cited $(n=19)$

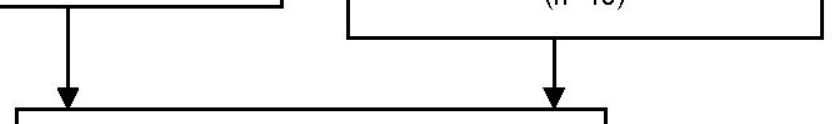

Records after duplicates removed

$(n=1,946)$
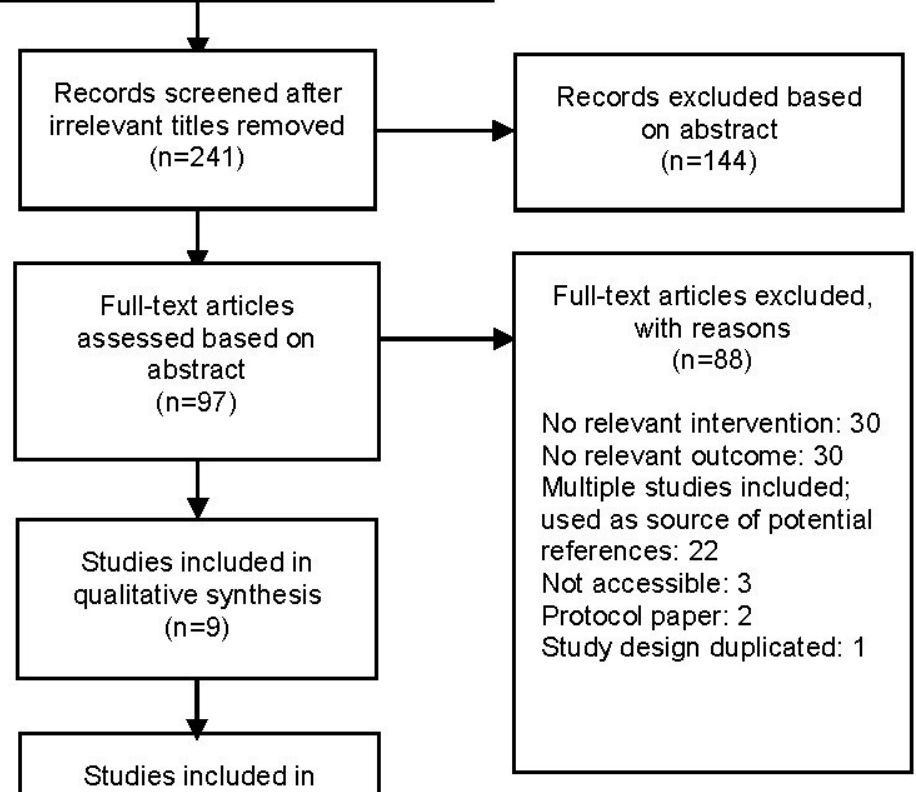

quantitative synthesis

(meta-analysis)

$$
(n=5)
$$




\section{LMPA}

Foley et al., 2015

24

2

Huang et al., 2017

24

2

Chang et al., 2017

12

1

Miller et al., 2015

12

2

Subtotal $($-squared $=73.6 \%, p=0.010)$

MVPA

Chang et al., 2017

12

Miller et al., 2015

12

Hong et al., 2016

5

Foley et al., 2015

24

Subtotal $(1-$ squared $=61.6 \%, p=0.050)$

Overall $(\mathrm{I}$-squared $=74.1 \%, \mathrm{p}=0.000)$

NOTE: Weights are from random effects analysis

$\begin{array}{ll}0.05(-1.01,1.11) & 16.80 \\ 2.00(-0.59,4.59) & 8.22 \\ 2.22(1.08,3.36) & 16.28 \\ 3.55(1.12,5.99) & 8.83 \\ 1.76(0.19,3.32) & 50.13\end{array}$

$0.39(-0.44,1.23)$

18.26

$5.06(1.19,8.92)$

4.68

$-0.03(-0.59,0.52) \quad 19.84$

$-1.24(-4.14,1.67) \quad 7.09$

$0.33(-0.71,1.38) \quad 49.87$

$1.06(0.12,2.01)$

100.00 